\title{
Gametophytic development of Brassica napus pollen in vitro enables examination of cytoskeleton and nuclear movements
}

\author{
Ewa Dubas • Maria Wedzony • Jan Custers • \\ Henk Kieft • André A. M. van Lammeren
}

Received: 11 March 2011 / Accepted: 11 May 2011 / Published online: 26 May 2011

(C) The Author(s) 2011. This article is published with open access at Springerlink.com

\begin{abstract}
Isolated microspores and pollen suspension of Brassica napus "Topas" cultured in NLN-13 medium at $18^{\circ}$ $\mathrm{C}$ follow gametophytic pathway and develop into pollen grains closely resembling pollen formed in planta. This culture system complemented with whole-mount immunocytochemical technology and novel confocal laser scanning optical technique enables detailed studies of male gametophyte including asymmetric division, cytoskeleton, and nuclear movements. Microtubular cytoskeleton configurationally changed in successive stages of pollen development. The most prominent role of microtubules (MTs) was observed just before and during nuclear migration at the early and mid-bi-cellular stage. At the early bi-cellular stage, parallel arrangement of cortical and endoplasmic
\end{abstract}

Communicated by Handling Editor: Pavla Binarova

Electronic supplementary material The online version of this article (doi:10.1007/s00709-011-0287-0) contains supplementary material, which is available to authorized users.

E. Dubas $\cdot$ H. Kieft $\cdot$ A. A. M. van Lammeren

Laboratory of Plant Cell Biology, Wageningen University,

Droevendaalsesteeg 1, Radix building 107, W1 6708 PB,

Wageningen, The Netherlands

E. Dubas $\cdot$ J. Custers

Plant Research International, Wageningen University,

Droevendaalsesteeg 1, 6708 PB, Wageningen, The Netherlands

E. Dubas $(\bowtie) \cdot$ M. Wedzony

Institute of Plant Physiology Polish Academy of Sciences,

ul. Niezapominajek 21,

30-239 Kraków, Poland

e-mail: dubas@ifr-pan.krakow.pl

M. Wedzony

Pedagogical University of Kraków,

Podchorążych 2,

30-084 Kraków, Poland
MTs to the long axis of the generative cell (GC) as well as MTs within GC under the plasmalemma bordering vegetative cell (VC) were responsible for GC lens shape. At the beginning of the GC migration, endoplasmic microtubules (EMTs) of the VC radiated from the nuclear envelope. Most cortical and EMTs of the VC were found near the sporoderm. At the same time, pattern of MTs observed in GC was considerably different. Multiple EMTs of the GC, previously parallel aligned, reorganized, and start to surround GC, forming a basket-like structure. These results suggest that EMTs of GC provoke changes in GC shape, its detachment from the sporoderm, and play an important role in GC migration to the vegetative nucleus (VN). During the process of migration of the $\mathrm{GC}$ to the $\mathrm{VC}$, multiple and thick bundles of MTs, radiating from the cytoplasm near GC plasma membrane, arranged perpendicular to the narrow end of the GC and organized into a "comet-tail" form. These GC "tail" MTs became shortened and the generative nucleus (GN) took a ball shape. The dynamic changes of MTs accompanied polarized distribution pattern of mitochondria and endoplasmic reticulum. In order to confirm the role of MTs in pollen development, a "wholemount" immunodetection technique and confocal laserscanning microscopy was essential.

Keywords Pollen grain - Cytoskeleton - Microtubules · Nucleus · Brassica napus

$\begin{array}{ll}\text { Abbreviations } \\ \text { CLSM } & \text { Confocal laser-scanning microscopy } \\ \text { 3-D } & \text { Three dimensional } \\ \text { DAPI } & 4^{\prime} .6 \text {-diamidino-2-phenylindole } * 2 \mathrm{HCl} \\ \text { DiOC }_{6} & \text { 3,3-dihexyloxacarbocyanine iodide } \\ \text { EGTA } & \text { Ethylene glycol tetraacetic acid } \\ \text { EMTs } & \text { Endoplasmic microtubules }\end{array}$

Abbreviations

CLSM Confocal laser-scanning microscopy

3-D Three dimensional

DAPI 4'.6-diamidino-2-phenylindole * $2 \mathrm{HCl}$

$\mathrm{DiOC}_{6} \quad$ 3,3-dihexyloxacarbocyanine iodide

EMTs Endoplasmic microtubules 


$\begin{array}{ll}\text { ER } & \text { Endoplasmic reticulum } \\ \text { GA } & \text { Glutaraldehyde } \\ \text { GC } & \text { Generative cell } \\ \text { GN } & \text { Generative nucleus } \\ \text { MTs } & \text { Microtubules } \\ \text { MTSB } & \text { Microtubule stabilizing buffer } \\ \text { NaN }_{3} & \text { Sodium azide } \\ \text { NLN-13 } & \text { Lichter medium } \\ \text { MQ water } & \text { Milli-Q water } \\ \text { PBS } & \text { Phosphate-buffered saline } \\ \text { PFA } & \text { Paraformaldehyde } \\ \text { PI } & \text { Propidium iodide } \\ \text { PIPES } & \text { 1.4-piperazinediethane sulfonic acid } \\ \text { PPB } & \text { Preprophase band } \\ \text { RT } & \text { Room temperature } \\ \text { VC } & \text { Vegetative cell } \\ \text { VN } & \text { Vegetative nucleus }\end{array}$

\section{Introduction}

In planta, microspores released from tetrads, are programmed to follow gametophytic developmental pathway and form mature pollen grains. The same process can be imitated also in in vitro conditions for some dicotyledonous species, e.g., Brassica napus, (Simmonds and Keller 1999; Touraev et al. 1997; Zonia et al. 1999). To secure proper gametophytic development, it is necessary to provide isolated microspores with medium reach in nutrients and controlled moderate temperature conditions $17.5-25^{\circ} \mathrm{C}$ (Binarova et al. 1993; Custers et al. 1994; Custers 2003; Hause et al. 1991, 1993; Joosen et al. 2007; Satpute et al. 2005; Simmonds and Keller 1999; Supena et al. 2008). Since pollen development is autonomously regulated, it can be studied in isolated microspore suspensions where it could be subjected to immunolabelling without the interfering presence of the anther tissue. Therefore, in vitro pollen culture potentially provides an excellent system for studying different aspects of cell biology such as cell polarity, patterning, cell fate determination, cellular differentiation, and signaling (Custers et al. 1994; Yamamoto et al. 2003).

During Brassica napus pollen gametophytic development, a sequence of events leads to the establishment of the cell polarity. It is necessary for the asymmetric mitotic division, and nuclear migration which accompanies pollen grain formation, differentiation, and maturation (Binarova et al. 1993; Custers et al. 1994; Custers 2003; Hause et al. 1991; Straatman and Satpute et al. 2005; Straatman and Schel 2001). Some of the complex cellular events leading to the differentiation of the male gametophyte were proposed to be mediated by the cytoskeleton (Gervais et al. 1994, 2000; Hause et al. 1991, 1993; Simmonds 1994; Simmonds and Keller 1999). The cytoskeleton reorganiza- tion is one of the first phenomenons in the living cell that precedes division and differentiation (Hause et al. 1991, 1993; Hepler and Hush 1996). In B. napus, the distribution and function of microtubules (MTs) were first studied by electron microscopy (Hause et al. 1993; Murgia et al. 1991) and then using immunocytochemistry with fluorescent probes (Gervais et al. 1994, 2000; Hause et al. 1991, 1993; Simmonds 1994; Simmonds and Keller 1999). Studies performed so far on Brassica pollen in vitro involved fixation with multiple centrifugations of the material and complicated embedding procedures followed by sectioning that narrowed application of fine immunolabeling protocols, and therefore, three dimensional (3D) structure of MT cytoskeleton was difficult to reconstruct (Gervais et al. 1994; Hause et al. 1991, 1993).

In microspore suspensions, the absence of tapetum allows us to elaborate modified protocol of immunolabeling and a whole mount staining of developing pollen which proves to be a perfect tool to show fine cellular details such as MT cytoskeleton, usually difficult to visualize. For the first time, the present study describes 3D changes in MT organization of in vitro cultured microspores and pollen. Moreover, our results confirm an important role of MTs in bicellular pollen development, polarization, and differentiation.

\section{Materials and methods}

\section{Donor plants}

Plants of B. napus L. "Topas", line DH 4079 were grown under greenhouse conditions at $20 / 18^{\circ} \mathrm{C}$ day/night temperature, with additional light (Philips SON-T lamps), at $16 \mathrm{~h} / 8 \mathrm{~h}$ day/night regime. At the beginning of bolting, they were transferred to a growth chamber where they grew at $10^{\circ} \mathrm{C}$ with 16-h illumination per day provided by $150 \mu \mathrm{E} \mathrm{m}^{-2} \mathrm{~s}^{-1}$ HPI (Philips). Plants were watered daily, twice a week with supplement of $\mathrm{N} / \mathrm{P} / \mathrm{K}=15: 15: 18$ soluble fertilizer. Inflorescences were harvested from plants kept at least for 2 weeks under these conditions. Flower buds of 3.4-3.5 mm in length were used for the isolation of microspores.

Microspore isolation and culture

Microspore isolation and culture were performed according to Custers (2003) with modifications by Joosen et al. (2007). Isolated microspores were cultured continuously in NLN-13-modified Lichter (1982) medium with 13\% sucrose $(w / v)$, without potato extract and growth regulators in 6-cm Petri dishes at $18^{\circ} \mathrm{C}$ in culture incubators (Marius Instruments or ST4/B/40 (Industrial Research Institute for Automation and Measurement)) to allow pollen maturation. Progress of microspore development in culture was mon- 
itored daily from the isolation day to the seventh day of culture, when mature pollen grains were found. At least 40 microspores or pollen grains per each day of culture were closely analyzed.

\section{Visualization of cell components}

Chromatin was stained either with 4'.6-diamidino-2phenylindole *2HCl (DAPI) (Sigma-Aldrich, D-9564) (0.0001\%) (absorption $365 \mathrm{~nm}$, emission $420 \mathrm{~nm}$, blue fluorescence) according to Custers et al. (1994), or with propidium iodide (PI) (Sigma-Aldrich, P-4170) (0.1\%) (absorption $536 \mathrm{~nm}$, emission $623 \mathrm{~nm}$, red fluorescence) according to Kallioniemi (1988). Mitochondria and ER were shown with $\mathrm{DiOC}_{6}$ (3,3-dihexyloxacarbocyanine D273) (absorption $483 \mathrm{~nm}$, emission $501 \mathrm{~nm}$, green fluorescence) $(0.0001 \%)$ according to Terasaki (1994). Samples of suspension $(100 \mu \mathrm{l})$ containing microspores and/or pollen were collected in Eppendorf tubes and incubated independently in DAPI and $\mathrm{DiOC}_{6}$, then drops of suspension were placed on slides and analyzed.

\section{Immunolocalization of microtubules}

The development of a "whole mount" immunolabelling protocol to visualize MTs in cultured microspores and pollen grains with confocal laser-scanning microscopy (CLSM) is a long and tedious process, and therefore, it is emphasized below. Critical points concern the use of handmade sieves to prevent centrifugation, a two-step fixation to maintain cell shapes while preserving antigenicity, improving accessibility for antibodies using a complex enzyme mixture, Triton X-100, and dimethyl sulfoxide (DMSO). These steps appeared all critical in obtaining results.

The protocol for a "whole-mount" immunolocalization was adapted from Friml et al. (2003) and SzechyńskaHebda et al. (2005) with substantial modification that enabled success in proper preservation of cell structures by fixation and subsequent proper penetration of antibodies to the MT cytoskeleton.

Samples of suspension were collected on handmade sieves prepared from "blue" pipette tips (5 $\mathrm{mm}$ in diameter) with nylon mesh (11 $\mu \mathrm{m}$, Millipore). All the subsequent steps of procedure were performed with the use of sieves that prevented loss of material and enabled us to avoid any centrifugation during procedure. Sieves with collected material were immediately placed for $10 \mathrm{~min}$ at RT in Eppendorf tubes in a freshly prepared prefixation mixture containing $1 \%$ paraformaldehyde (PFA, Sigma 76240) and $0.025 \%$ glutaraldehyde (GA, Sigma 49626) in microtubule-stabilizing buffer [MTSB, $50 \mathrm{mM}$ 1,4piperazinediethane sulfonic acid (PIPES, Sigma P-1851), 5 mM EGTA (Sigma O-3778), $5 \mathrm{mM} \mathrm{MgSO}_{4}, \mathrm{pH} 7.0$, adjusted with $5 \mathrm{M} \mathrm{KOH}$. The first fixative was removed from Eppendorf tubes. Next, cells were re-dipped in 3\% PFA/ $0.025 \%$ GA in MTSB for $30 \mathrm{~min}$ at RT. Samples were washed with MTSB $/ 0.025 \%$ Triton X-100 $(1 \times 10 \mathrm{~min})$, treated with a $0.05 \mathrm{M} \mathrm{NH}_{4} \mathrm{Cl}$ and $0.05 \mathrm{M} \mathrm{NaBH}_{4}(5 \mathrm{~min})$, and washed again. To make microspore and pollen walls permeable to antibodies, they were partly digested in a mixture of 1\% cellulase ("Ozonuka R-10" from Trichoderma viride, SERVA 16419), $0.8 \%$ pectinase (from Rhizopus, SIGMA P-2401), 0.02\% pectolyase (from Aspergillus japonicus, SIGMA P-3026), and 0.3\% macerozyme (R-10 from Rhizopus lyophil, SERVA 28302) in MTSB for $1 \mathrm{~h}$ at $37^{\circ} \mathrm{C}$. Then cells were washed with MTSB $/ 0.025 \%$ Triton X-100 $(5 \times 10 \mathrm{~min}$ each). From that point onward, protocols described by Friml et al. (2003) and Szechyńska-Hebda et al. (2005) were applied with minor variations. To enhance wall and cell membrane permeability further, the material was incubated in $10 \% \mathrm{DMSO} / 3 \%$ Nonidet P-40 in MTSB for $50 \mathrm{~min}$ at RT. After rinsing, a blocking step was performed with $2 \%$ BSA in MTSB at $30^{\circ} \mathrm{C}$. Primary, monoclonal antibodies were applied in $3 \%$ BSA/MTSB at $4^{\circ} \mathrm{C}$ overnight (anti- $\alpha$-tubulin clone DM1A raised in mouse, dilution 1:1,000, Sigma T-9026). Cells were washed six times 10 min with MTSB $/ 0.025 \%$ Triton (washing buffer), after which the secondary antibody GaM/IgG/Alexa 488 (Molecular Probes A-11001, dilution 1:100) was applied in blocking buffer for $3 \mathrm{~h}$ at $37^{\circ} \mathrm{C}$ in darkness. Thereafter, material was washed with $\mathrm{MTSB} / 0.025 \%$ Triton $/ 0.02 \%$ $\mathrm{NaN}_{3}$ (six times $10 \mathrm{~min}$ ) and with sterile MQ water (six times $10 \mathrm{~min}$ ). Samples were stored in PBS containing 0.02\% $\mathrm{NaN}_{3}$. Control experiments were performed by omitting the first antibody. For DNA counterstaining, the samples were incubated in PI $\left(0.1 \%\right.$ in $\left.\mathrm{H}_{2} \mathrm{O}\right)$ for 15 min, washed in PBS, and embedded on slides in Citifluor glycerol (Citifluor Ltd. in glycerol, AF2, Enfield Cloisters).

\section{Microscopic observation}

CLSM and fluorescence microscopy was done with CELL MAP IC Bio-Rad (Microscience Division, Hemel Hempstead, UK) confocal, mounted on a Nikon Eclipse TE 2000-S inverted microscope. Fluorescence was examined under filters EX 365/DM 400/BA 420 EF: (DAPI); EX 470490/DM $510 \mathrm{BA} / 515 \mathrm{EF}$ (Alexa 488 and $\mathrm{DiOC}_{6}$ ) and EX 510-560/DM 580 BA/590 EF (PI). CLSM images were collected by Kalman averaging of four full scans. Three-dimensional images and z-projections of the cells were obtained by collecting series of approximately 30 60 optical sections in the $Z$-axis, each section 0.5 to $1-\mu \mathrm{m}$ thick. Images were acquired and processed using software programs including Lasersharp 2000 software (microscience Division, Hemel Hempstead, UK), Confocal assistant 4.02 (written by Todd Clark Brelje) CorelDRAW ${ }^{\circledR}$ 
ESSENTIALS 9.0, and Adobe Photoshop 5.0 (Adobe Systems, Mountain View, CA, USA).

\section{Results}

Suspension at the time of isolation

Freshly isolated suspensions contained mostly microspores at late uninucleate stage of development with diameter ranging from 15 to $20 \mu \mathrm{m}$ (Fig. 1a, b(1), and (2)). Microspores were spherical, surrounded with sporoderm divided into three lobes by three colpi or furrows (Figs. 1a, $b(1)$, and (2)). A big, central vacuole occupied most of the microspore volume, thus, the cytoplasm and nucleus were located peripherally (Fig. $1 \mathrm{a}$ and $\mathrm{b}(1)$ ). Analysis with $\mathrm{DiOC}_{6}$ revealed intensive fluorescence in the cytoplasm near nucleus, what indicated the concentration of mitochondria and ER in this region (Fig. 1b(1)).

The first pollen division

The first pollen mitosis was preceded by chromatin condensation typical for the prophase stage (Fig. 1c), while preprophase band (PPB) of MTs was not spotted prior to the first pollen mitosis. Two days after isolation procedure in many cells, the first pollen mitosis took place in vicinity of sporoderm, with axis perpendicular to the wall (Fig. 1d(1)-(2)). Acentric spindle gave rise to the asymmetric division of the cell (Fig. 1e(1)-(5) and f).

Between the third and seventh day of culture, numerous structures of circa $30 \mu \mathrm{m}$ in diameter closely resembling bicellular pollen grains were observed (Figs. 1e(1)-(5), f and 2). The shapes and positions of the cells were very similar
Fig. 1 Early stages of gametophytic development of Brassica napus "Topas" microspores at non-embryogenic conditions $\left(18^{\circ} \mathrm{C}\right)$. a-b Microspores at uninucleate and vacuolate stage. Acentrally located nucleus. b 1 Peripheral and polar located mitochondria and ER in the cytoplasm. b 2 Microspore sporoderm divided into three lobes by three colpi or furrows. c Prophase chromosomes. d 1-2 Metaphase. Chromosomes (d l) and spindle (d 2) in a position normal for gametophytic development. e 1-5 Successive optical sections from bi-cellular pollen grain with small GC close to the sporoderm wall and large VC. e 1 Cortical MTs. e 2 Subcortical MTs. e 3-4 Endoplasmic MTs. Note the dense array of MTs demarcating the GC (arrow). f GN and VN of bi-cellular pollen grain. a, c, $\mathbf{f}$ Nuclei visualized with UV after DAPI staining. b 1 Mitochondria and ER visualized with $\mathrm{DiOC}_{6}$ (green). b 2 DIC image. d 1 , e 5 . DNA after PI staining visualized with TRITC (red). d 2, e 1-4. MTs in microspores visualized immunocytochemically with FITC (green)
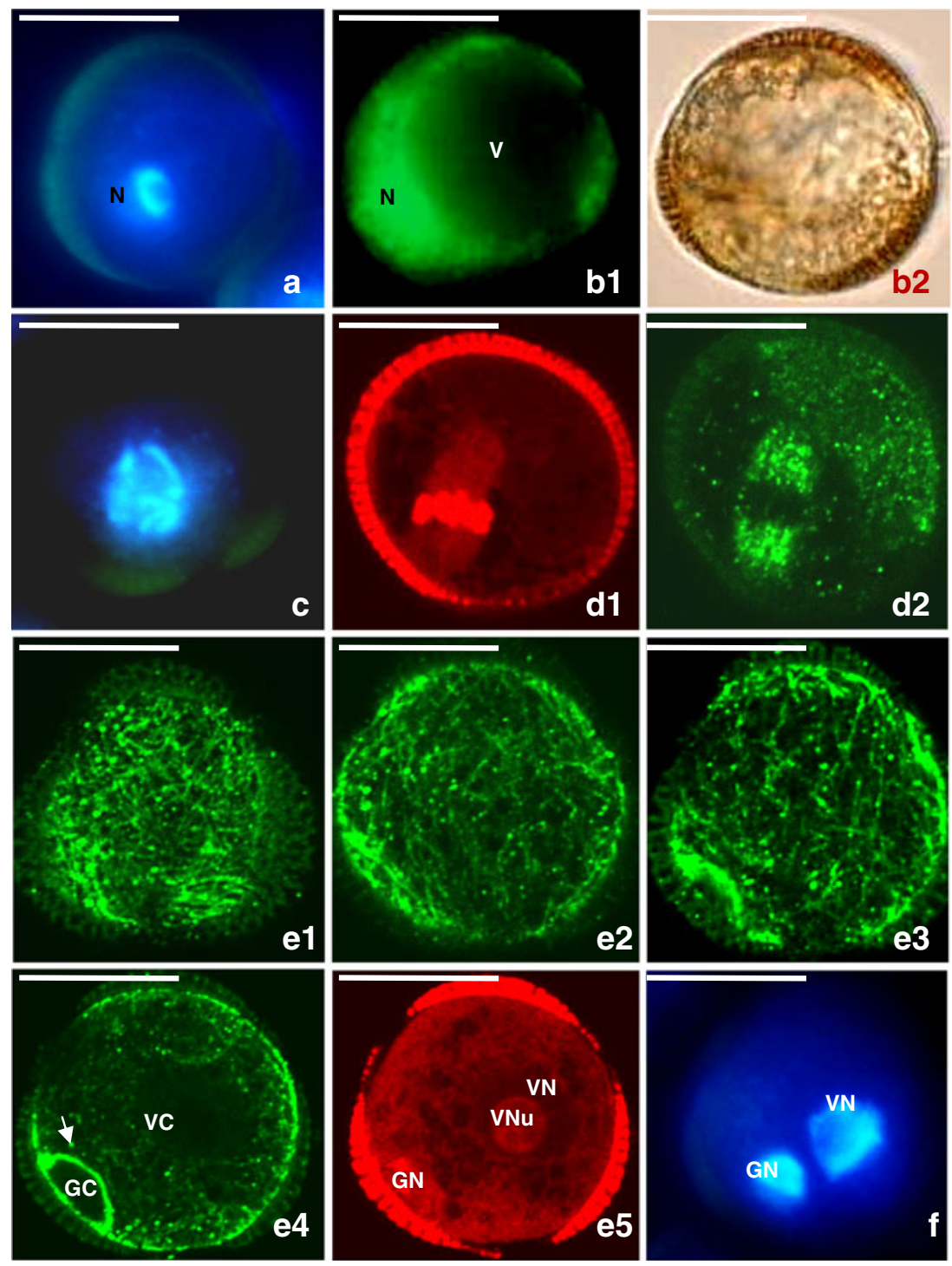
to that of the GC and the VC of Brassica sp. pollen grain developing in planta; therefore, we use the relevant names of the cells in the further description.

Initially, GC occupied lens-shaped space close to the wall, and $\mathrm{VC}$ was much larger and occupied almost the whole space within the sporoderm (Fig. 1e(4)-(5)). The MT network in the cortical, sub-cortical, and cytoplasmic layer was more prominent in the region where GC was located. However, MT network was particularly dense within GC under the plasmalemma bordering VC (Fig. 1e(2)-(4)). Those multiple and thick bundles of MTs were arrayed parallelly to the longer axis of GC. Such MTs configuration caused GC lens shape. Bundles of parallel MT were also found within the $\mathrm{VC}$ in vicinity of GC; however, those had looser arrangement in comparison to MT found in GC (Fig. 1e(2)-(4)). In the cytoplasm of VC adjacent to both narrow edges of GC, bundles of parallel MT expanded underlying sporoderm wall (Fig. 1e(3)-(4)). They were gradually loosing the parallel order to the networking one, typical to the remaining region of $\mathrm{VC}$ cytoplasm underlying the sporoderm, i.e., cortical cytoplasm (Fig. 1e(1)-(4)). The deeper regions of VC cytoplasm of early bi-cellular pollen grain contained brightly labeled randomly oriented MTs of various lengths (Fig. 1e(1)-(4), Online resources 1a, b). Vacuoles were not observed in GC, while a number of vacuoles of various sizes were observed in VC (Fig. 1e(4)-(5)). Staining with PI displayed in microspore intensely fluorescent mitotic chromosomes (Fig. 1d(1)), while the visualization of both bicellular pollen grain nuclei gave very faint fluorescence at the early stage after division (Fig. 1e(5)). DAPI staining gave good results at all developmental stages (Fig. 1a, c, and f).

Before its mitosis, GC migrates to a more central position within VC (Fig. 2). At the start of GC migration, multiple and longitudinal bundles of MTs, surrounding GC in its central region, could be distinguished in the majority of optical sections (Online resource 2). Those MTs bundles oriented perpendicular to the long axis of GC and formed cortex, which partially covered GC (Online resource 2). Such MTs configuration around GC successively changed during its further migration and formed a structure, which probably protects GC.

Dense organized MTs network surrounded GC all the time during its migration to the center of the VC, while GC and its nucleus became more spherical (Fig.2a-e). The distribution of the remaining VC MTs was changing during GC migration. At the beginning of this process, MTs radiated from the nuclear envelope of the $\mathrm{VN}$, and most of them were found near the sporoderm (Fig. 2a(1)). At that time, multiple MTs of the GC surrounded its nucleus and formed a basket-like structure (Fig. 2a(1), b, c, and d, Online resource 2). When GC took more central position within $\mathrm{VC}$, a bunch of thick and longitudinally arranged MTs, radiating from the cytoplasm near GC plasma membrane, was observed. These MTs assembled in the narrow end very close to the nucleus of $\mathrm{VC}$ and formed a structure resembling the tail of a comet (Fig. 2c and e(2), Online resource 3). In the subcortical cytoplasmic region of bi-cellular pollen, a number of very fine MTs with faint fluorescent signal extended, forming a network (Fig. 2e(1) (3)). At the same time, in the cytoplasm of the VC, multiple MTs formed ring of MTs (Fig. 2e(2)). MTs came from the GC, shortened, and the GC and GN became ball-shaped (Fig. 2e(2)). At this stage of pollen development, analysis with $\mathrm{DiOC}_{6}$ revealed intensive fluorescence in the cytoplasm near both nuclei, what indicated the large amount of mitochondria and ER in these regions (Fig. 2f).

The second pollen mitosis

Changes in vacuolization pattern and in volume of the cells preceded the second pollen mitosis, i.e., division of the GC. Mitosis resulted in the formation of male gametes: the two sperm cells (Fig. $2 \mathrm{~g}(1)$ and (2)). Finally, tri-cellular ellipsoidal pollen was formed with multiple vacuoles dispersed in the cytoplasm of the VC (Fig. 2g(1)-(2)). Sperm cells were elongated and situated very close to each other. Staining with $\mathrm{DiOC}_{6}$ revealed intensive fluorescence in the cytoplasm close to all nuclei, what indicated the large amount of mitochondria and ER in these regions (Fig. $2 \mathrm{~g}(1)$ ). Tri-cellular pollen grain formed in vitro was wider in the major diameter ca. $50 \mu \mathrm{m}$ and in the smaller diameter ca. $20 \mu \mathrm{m}$ and was surrounded by the sporoderm. The shape of pollen was similar to that observed in pollen grains in planta.

\section{Discussion}

\section{Technical advance}

The immunofluorescence protocol presented here, deviated from earlier protocols described by Friml et al. (2003) and Szechyńska-Hebda et al. (2005) with respect to the material fixation (pre- and post-fixation), washing steps, and enzymatic digestion. Instead of a single fixation with 4\% PFA (Friml et al. 2003) and two-steps fixation in 2\% PFA and 4\% PFA (Szechyńska-Hebda et al. 2005), samples were prefixed in $1 \%$ PFA with $0.025 \%$ GA followed by $3 \%$ PFA with $0.025 \%$ GA. Further improvement of cytoskeleton preservation was achieved by samples washings at the lowered concentration of Triton X-100 in MTSB, in comparison to Friml et al. (2003) and Szechyńska-Hebda et al. (2005). As the figures and confocal multilayer scans of entire cells in this paper prove, this combination of fixatives and washes preserve ideally fine cellular structures without disturbing their immunonological properties, therefore, they can be recommended for use in any immunolabeling protocols. 

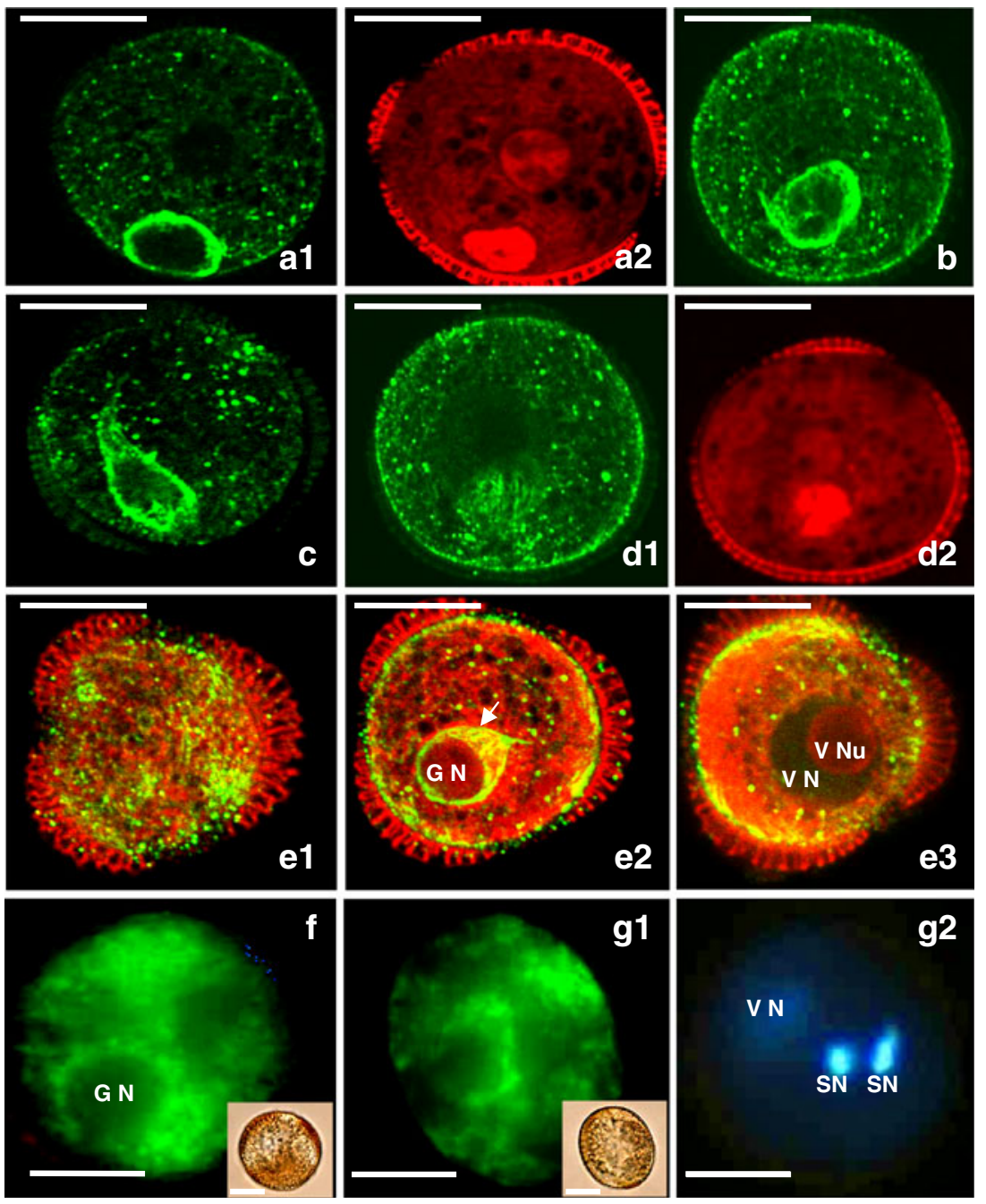

Fig. 2 Pollen of Brassica napus "Topas" after culture at nonembryogenic conditions $\left(18^{\circ} \mathrm{C}\right)$. a $1-\mathbf{f}$ Bi-cellular pollen grain. a 1 Multiple MTs of the GC cytoplasm enclosed the migrating GC. a 2 Section as in a 1. GN and VN. b MTs surrounded spherical GN, which migrated to the center of the VC. c MTs attaining spindle shape around GN. d 1 MTs formed basket like structure around GN. d 2 Section as in d 1 GN close to the VN. e $1-3$ Successive optical sections. e 1 CMTs network underlying sporoderm wall. e 2 Endoplasmic MTs came from the GC shortened and moved to the VC. The GN became ball-shaped (arrow). e 3 Nucleolus (VNu) of

Low permeability of sporoderm to antibodies was the next technical problem overcome in this study. Friml et al. (2003) used $2 \%$ driselase for digestion of cell walls in suspension, while Szechyńska-Hebda et al. (2005) applied and $2 \%$ driselase, $1 \%$ cellulase, and $0.5 \%$ pectolyase. Both mixtures were not successful in our hands when used for sporoderm digestion. The mixture applied in this study was composed of $1 \%$ cellulase, $0.8 \%$ pectinase, $0.02 \%$ pectolyase, and $0.3 \%$ macerozyme in MTSB $/ 0.025 \%$ Triton X100. Sporoderm digestion enabled whole-mount immunolabelling giving us unique opportunity to document 3D structure of MT cytoskeleton. Combination of excellent
VN. Endoplasmic MTs formed ring in the thin layer of cytoplasm of the VC. f Mitochondria and ER in the cytoplasm near GN and VN nuclei of pollen. g $1-2$ Tri-cellular pollen grain. $\mathbf{g} 1$ Mitochondria and ER in the cytoplasm near both nuclei of pollen. $\mathbf{g} 2$ Section respective to $\mathrm{g} l \mathrm{VN}$ and two sperm cell nuclei (SN) during the formation of the male germ unit. a $1, \mathbf{b}, \mathbf{c}, \mathbf{d} 1, \mathbf{e} 1-3$. MTs in microspores visualized immunocytochemically with FITC (green). a 2, d 2, e 2-3. DNA after PI staining visualized with TRITC (red). $\mathbf{f}-\mathbf{g} 1$ Mitochondria and ER visualized with $\mathrm{DiOC}_{6}$ (green); insets show DIC image. g 2 Nuclei visualized with UV after DAPI staining

MTs labeling with high-quality confocal imaging added unique information about MTs arrays in successive stages of pollen grain development, especially precious for multistep bi-cellular stage of pollen development, which was not precisely described before in the literature.

Microtubule configurations in pollen grain

Microspore cultures of B. napus were used to study in vitro pollen development (Custers et al. 1994; Custers 2003; Hause et al. 1993; Joosen et al. 2007; Simmonds and Keller 1999). In B. napus microspore and pollen culture develop- 
ing at $18^{\circ} \mathrm{C}$ or at $25^{\circ} \mathrm{C}$, the changes in MTs cytoskeleton clearly coincide with majority of events leading to the formation and differentiation of pollen grains (Hause et al. 1991, 1993; Simmonds and Keller 1999). Our data report, complete, and widen knowledge concerning fine differences of MT cytoskeleton organization in the cortical region of cytoplasm versus the endoplasmic region from early to late phase of pollen development, what was not precisely reported before. Moreover, our results outlined the important role of endoplasmic MTs in the GC migration.

Most of the previous reports describing cytoskeletal changes in Brassica pollen development were based on sectioned material (Gervais et al. 1994, 2000; Hause et al. 1991, 1993; van Lammeren et al. 1985), and only a single paper based on non-sectioned cells (Simmonds and Keller 1999). Hause et al. (1991) and Simmonds and Keller (1999) described mainly microspores and early bi-cellular pollen grains developing in planta. Incidental data are available on MT organization in microspores cultured in vitro at $18^{\circ} \mathrm{C}$ (Hause et al. 1993) or $25^{\circ} \mathrm{C}$ (Simmonds and Keller 1999). Moreover, survey of changes in MT configuration and their control role during pollen nuclear migration have never been analyzed in 3D. The presented results nicely complete previous studies on in vitro pollen development, and add some interesting information about MT arrays at successive stages of bi-cellular pollen differentiation. Based on our observations, we can conclude that microspores and pollenlike structures of $B$. napus developed in vitro displayed cortical MT arrangement in the VC of early bi-cellular pollen grain similar to that observed in planta (Hause et al. 1991; Simmonds and Keller 1999). Our results gave new insight on the role of two kinds of GC MTs: the first surrounding a free $\mathrm{GC}$ and the second, perpendicular to the longer axis of $\mathrm{GC}$, following $\mathrm{GC}$ up to the $\mathrm{VN}$.

Our observation is in agreement with previously provided coverage that the first asymmetric mitosis is not preceded with PPB formation. PPB predicts the site of the future division plate in somatic cells (Hause et al. 1991). The absence of PPB in microspore mitosis was earlier reported for Brassica by Hause et al. (1993), Gasteria (van Lammeren et al. 1985), and for Tradescantia (Terasaka and Niitsu 1990).

Our investigations confirmed that the mitotic, acentric spindle was oriented perpendicular to the sporoderm and that after division, young bi-cellular pollen grain was formed containing GC and VC (Fan et al. 1988). GC has a thin wall and remains peripheral in the early bi-cellular stage of pollen development (Boavida et al. 2005). We have discovered that at that stage of pollen development, multiple and thick boundless of MTs in sub-cortical and cytoplasmic layers arranged longitudinally to the longer axis of $\mathrm{GC}$, while cortical MTs delicate surrounded GC. Configuration of endoplasmic and sub-cortical MTs caused GC spindle shape. It is interesting that in the later stages of pollen development, the trajectory orientation of GC migration was perpendicular to the orientation of these MTs. Nobody before observed such phenomena in pollen cultured in vitro.

The analysis of pollen, before the onset of the second mitosis, mainly confirmed previous findings, like the gradual disappearance of the large vacuole and the GC migration to a more central position or the differences in chromatin condensation of the vegetative-like cell and the generative-like cell in bi-cellular pollen like structure (Custers et al. 1994; Hause et al. 1993; Simmonds and Keller 1999). However, obtained results are not in agreement with previous data at some points and gave new, additional information. Simmonds and Keller (1999), showed a long CMT strand that appeared to extend from the cross wall between the two daughter cells (VC and GC) across the VC in bi-cellular pollen grain. Such MT strand was not detected in our study. Short cortical and endoplasmic MTs had disordered orientation in the VC with exception of the region bordering plasmalemma, the VC cytoplasm adjacent to both narrow edges of GC.

As in several other studies performed with the use of pollen developing in planta, a comet-like MT tail was formed around the GC migrating towards the center of VC. This confirms close similarities between in planta and in vitro pollen development, and its autonomous character. This observation supports ideas of Terasaka and Niitsu (1990), who described similar arrays as causing displacement of nucleus to the more central position in the cell. Previous literature data did not describe MT networks during nuclear migration in the dicotyledons including Brassica (Hause et al. 1991, 1993). Moreover, that unique MT arrays function at subsequent stages of pollen development, and it is the main feature of pollen cultured at nonembryogenic in vitro conditions (Hause et al. 1993). Murgia et al. (1991) observed in the electron microscope only a row of CMTs oriented along the long axis of the GC. At the same time, Hause et al. (1991) reported the cytoplasm of lens-shaped GC densely stained by fluorescent MTs in the microspores developing in planta. However, mentioned authors did not clearly point out the important role of EMTs in GN migration to the vicinity of the $\mathrm{VN}$, what preceded the second pollen mitosis and led to B. napus mature pollen formation. From our detailed 3D analysis of MT cytoskeleton (attached avi Supplementary material), we can conclude that EMTs, which surrounded $\mathrm{GC}$ at the beginning of its migration to the $\mathrm{VC}$, provoked changes in GC shape, its detachment from the sporoderm and its migration to the VN. At the same time, cortical MT of $\mathrm{GC}$, which formed basket-like structure around $\mathrm{GC}$, could play protective role during GC migration.

After detachment from the pollen wall, the GN rounds up to become spherical. In the dicot Brassica, microtubule networks play important role in nuclear migration. 
Subsequently, the GC undergoes further morphogenesis to form an elongated, lenticular, or spindle shape (reviewed in Palevitz and Tiezzi 1992). The morphogenesis of GC is associated with the reorganization of MT arrays within the cortical GC cytoplasm. In monocots and dicots, both MTs and $\mathrm{AFs}$ are involved in the asymmetric mitosis of the GC in mature pollen (Zonia et al. 1999).

Staining with $\mathrm{DiOC}_{6}$ of $B$. napus pollen grains revealed in our experiments intensive fluorescence in the cytoplasm near both nuclei (vegetative and generative one), what indicates abundant mitochondria, ER, and Golgi vesicles in these regions. We observed the increase in the intensity of fluorescence after $\mathrm{DiOC}_{6}$ in successive stages of pollen development, what was also reported by Nagata et al. (2000). The ultrastructure of the VC of B. napus pollen grains was reported by Charzynska et al. (1989) and Murgia et al. (1991). The VC was regarded as a highly differentiated and metabolically active fat-storage cell full of mitochondria with a well-developed internal membrane system, starchless plastids, microbodies, lipid bodies, dictyosomes, and numerous vesicles thought to originate from the dictysomes. Rough ER organized in stacks of cisternae was described as spatially associated with certain organelles, mainly lipid bodies, microbodies, and plastids. The authors speculated that the microbodies were involved in the conversion of lipid reserves to carbohydrates in the late period of VC maturation. Therefore, on the seventh day of culture, starch grains fill almost the whole cytoplasm of pollen grains. At this time of culture, Brassica pollen grains were tri-cellular.

In the Asteraceae, Arabidopsis, Brassica, and other plants with tri-cellular pollen, mitosis results in the formation of male gametes: the two sperm cells. They are elongated, with little cytoplasm, and are linked together. One of them is also connected to the nucleus of the $\mathrm{VC}$ so that they form a remarkable structure, which Dumas et al. (1985) called the male germ unit (Lalane and Twell 2002). MT arrays surrounded GC appears to be essential for the GC shape change from spherical to disc shape.

The presented report shows microspore cultures of $B$. napus as a model for fundamental studies. Based on $3 \mathrm{D}$ images, we have presented the role of microtubular cytoskeleton during bi-cellular in vitro pollen development, polarization, and differentiation.

Conflict of interest The authors declare that they have no conflict of interest.

Open Access This article is distributed under the terms of the Creative Commons Attribution Noncommercial License which permits any noncommercial use, distribution, and reproduction in any medium, provided the original author(s) and source are credited.

\section{References}

Binarova P, Straatman K, Hause B, Hause G, Van Lammeren AAM (1993) Nuclear DNA synthesis during the induction of embryogenesis in cultured microspores and pollen of Brassica napus. Theor Appl Genet 87:9-16

Boavida LC, Becker JD, Feijo JA (2005) The making of gametes in higher plants. Int J Dev Biol 49:595-614

Charzynska M, Murgia M, Cresti M (1989) Ultrastructure of the vegetative cell of Brassica napus pollen with particular reference to microbodies. Protoplasma 152(1):22-28

Custers JBM (2003) Microspore culture in rapeseed (Brassica napus L.). In: Maluszynski M, Kasha KJ, Forster BP, Szarejko I. (eds) Doubled haploid production in crop plants - the manual. Kluver Academic Publisher, pp. 185-194

Custers JBM, Cordewener JHG, Nöllen Y, Dons HJM, van Lookeren Campagne MM (1994) Temperature controls both gametophytic and sporophytic development in microspore cultures of Brassica napus. Plant Cell Rep 13:267-271

Dumas C, Knox RB, Gaude T (1985) The spatial association of the sperm cell and vegetative nucleus in the pollen grain of Brassica. Protoplasma 124:168-174

Fan Z, Armstrong KC, Keller WA (1988) Development of microspores in vivo and in vitro in Brassica napus L. Protoplasma 147: 191-199

Friml J, Benkova E, Mayer U, Palme K, Muster G (2003) Automated whole mount localisation techniques for plant seedlings. Plant $\mathrm{J}$ 34(1):115-124

Gervais C, Newcomb W, Simmonds DH (2000) Rearrangement of the actin filament and microtubule cytoskeleton during induction of microspore embryogenesis in Brassica napus cv. Topas Protoplasma 213:194-202

Gervais C, Simmonds DH, Newcomb W (1994) Actin microfilament organization during pollen development of Brassica napus cv. Topas Protoplasma 183:67-76

Hause B, Hause G, Pechan P, van Lammeren AAM (1993) Cytoskeletal changes and induction of embryogenesis in microspore and pollen cultures of Brassica napus L. Cell Biol Intern 17(2):153-168

Hause G, Hause B, van Lammeren AAM (1991) Microtubular and actin filament configurations during microspore and pollen development in Brassica napus cv. Topas Can J Bot 70:1369-1376

Hepler PK, Hush JM (1996) Behavior of microtubules in living plant cells. Plant Physiol 112(2):455-461

Joosen R, Cordewener J, Supena EDJ, Vorst O, Lammers M, Maliepaard Ch, Zeilmaker T, Miki B, America T, Custers J, Boutilier K (2007) Combined transcriptome and proteome analysis identifies pathways and robust markers associated with the establishment of Brassica napus microspore-derived embryo development. Plant Physiol 144:155-172

Kallioniemi OP (1988) Comparison of fresh and paraffin-embedded tissue as starting material for DNA flow cytometry and evaluation of intratumor heterogeneity. Cytometry 9:164-169

Lalane E, Twell D (2002) Genetic control of male germ unit organization in Arabidopsis. Plant Physiol 129:865-875

Lichter R (1982) Induction of haploid plants from isolated pollen of Brassica napus. Z Pflanzenphysiol 105:427-433

Murgia M, Detchepare S, Van Went JL, Cresti M (1991) Brassica napus pollen development during generative cell and sperm cell formation. Sex Plant Reprod 4:176-181

Nagata N, Saito C, Sakai A, Kuroiwa H, Kuroiwa T (2000) Unique positioning of mitochondria in developing microspores and pollen grains in Pharbitis nil: mitochondria cover the nuclear surface at specific developmental stages. Protoplasma 213(1-2):74-82 
Palevitz BA, Tiezzi A (1992) The organization, composition, and function of the generative cell and sperm cytoskeleton. Int Rev Cytol 140:149-185

Satpute GK, Long H, Seguí-Simarro JM, Risueño MC, Testillano PS (2005) Cell architecture during gametophytic and embryogenic microspore development in Brassica napus L. L Acta Physiol Plant 27(4B):665-674

Simmonds DH (1994) Mechanism of induction of microspore embryogenesis in Brassica napus: significance of the preprophase band of microtubules in the first sporophytic division. In: Akkas N (ed) Biomechanics of active movement and division of cells, NATO ASI series. Springer, Berlin, pp 569-574

Simmonds DH, Keller WA (1999) Significance of preprophase bands of microtubules in the induction of microspore embryogenesis of Brassica napus. Planta 208:383-391

Straatman KR, Schel JHN (2001) Distribution of splicing proteins and putative coiled bodies during pollen development and androgenesis in Brassica napus L. Protoplasma 216:191-200

Supena EDJ, Winarto B, Riksen T, Dubas E, van Lammeren A, Offringa R, Boutilier K, Custers J (2008) Regeneration of zygotic-like microspore-derived embryos suggests an important role for the suspensor in early embryo patterning. J Exp Bot 59 (4):803-814
Szechyńska-Hebda M, Wędzony M, Dubas E, Kieft H, van Lammeren AAM (2005) Visualization of microtubules and actin filaments in fixed BY-2 cells using an optimized whole mount labeling protocol. Plant Cell Rep 25:758-766

Terasaka O, Niitsu T (1990) Unequal cell division and chromatin differentiation in pollen grain cells. II. Microtubule dynamics associated with the unequal cell division. Bot Mag Tokyo 103:133-142

Terasaki M (1994) Labeling of endoplasmic reticulum with $\operatorname{DiOC}_{6}(3)$. In: Celis $\mathrm{J}$ (ed) Cell biology: a laboratory handbook, 2nd edn. Academic, Orlando, FL, pp 381-386

Touraev A, Vicente O, Herbele-Bors E (1997) Initiation of microspore embryogenesis by stress. Trends Plant Sci 2:285-323

Van Lammeren AAM, Keijzer CJ, Willemse MTM, Kieft H (1985) Structure and function of the microtubular cytoskeleton during pollen development in Gasteria verrucosa (Mill.) H Duval. Planta 65:1-11

Yamamoto Y, Nishimura M, Nishimura IH, Noguchi T (2003) Behavior of vacuoles during microspore and pollen development in Arabidopsis thaliana. Plant Cell Physiol 44(11):1192-1201

Zonia L, Tupý J, Staiger ChJ (1999) Unique actin and microtubule arrays co-ordinate the differentiation of microspores to mature pollen in Nicotiana tabacum. J Exp Bot 50(334):581-594 